\title{
Perancangan Sistem Kontrol CNC Pengebor PCB Otomatis Berbasis Raspberry PI
}

\author{
Eka Satrio $^{1)}$, Koko Joni' ${ }^{2)}$, dan Kunto Aji Wibisono ${ }^{3)}$ \\ 1, 2), 3) Jurusan Teknik Elektro, Fakultas Teknik, Universitas Trunojoyo Madura \\ 1,2), 3) Jl. Raya Telang, Perumahan Telang Indah, kamal, Kabupaten Bangkalan, Jawa Timur

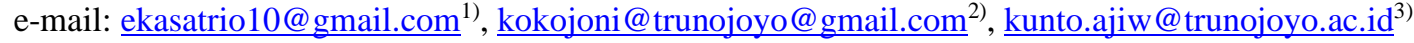

\begin{abstract}
Circuit Board $(P C B)$ is a micro-board containing various components electronics used in an automatic circuit. In PCB drilling is usually done human which takes a lot $\}$ when the hole in the PCB is getting more and more. And it takes precision when the eye touches the PCB board which gives rise to friction force and can cause drilling. The purpose of this research was the development of tools in the form of automated drills using computers with BCNC software as face-to-face CNC movements. The engine is driven with stepper motor and dc motor as spindle. In this BCNC software the drilling process is done by entering the codes in the form of gcode which can later be read by CNC. The coordinates of the holes in the layout that have been created are obtained by converting the layout into codes called gcode. The process is carried out using PCB designer software. Thoroughness testing on all six axes found an error 1,2\% with ten attempts each. PID implementation on $D C$ motor obtained constant value $K p=54, K i=38$ and $K d=0.9$. As well as before drilling, the installation of drill bits must be precise so that at the time of spinning, the drill bits do not shake.
\end{abstract}

Keywords: $C N C, P C B, B C N C$.

\begin{abstract}
ABSTRAK
Printed Circuit Board (PCB) merupakan sebuah papan berukuran mikro (kecil) yang berisi berbagai komponen elektronika yang digunakan dalam suatu rangkaian yang bersifat otomatis. Pada pengeboran PCB ini biasanya dilakukan secara manual dengan tenaga manusia, yang membutuhkan banyak waktu ketika lubang pada PCB tersebut semakin banyak. Serta dibutuhkan kepresisian ketika mata bor menyentuh papan PCB yang menimbulkan gaya gesek dan dapat menyebabkan salah pengeboran. Tujuan dari penelitian ini pengembangan alat berupa bor otomatis menggunakan komputer dengan perangkat lunak BCNC sebagai tatap muka pergerakan CNC. Mesin ini digerakkan dengan motor stepper dan motor DC sebagai spindle. Pada software $B C N C$ ini proses pengeboran dilakukan dengan memasukkan kode-kode berupa gcode yang nantinya dapat terbaca oleh CNC. Koordinat lubang pada layout yang telah dibuat didapatkan dengan cara mengkonversi layout ke dalam kode-kode yang disebut gcode. Proses tersebut dilakukuan dengan menggunakan software PCB designer. Pengujian ketelitian pada keenam sumbu didapat nilai error 1,2\% dengan masing-masing sepuluh kali percobaan. Implementasi PID pada motor DC didapatkan nilai konstanta $\mathrm{Kp}=54, \mathrm{Ki}=38$ dan $\mathrm{Kd}=0.9$. Serta sebelum melakukan pengeboran, pemasangan mata bor harus presisi agar pada saat berputar, mata bor tidak goyang.
\end{abstract}

Kata Kunci: CNC, PCB, BCNC.

\section{Pendahuluan}

$\mathrm{D}$ i era modern saat ini, rangkaian elektronika dapat bekerja hanya dengan chip yang ukurannya semakin kecil yang dapat disebut sebagai mikrokontroler. Chip mikrokontroler ini dibuat pada suatu wadah yang bernama PCB. PCB (Printed Circuit Board) adalah suatu papan kecil (mikro) yang penuh dengan sirkuit dengan bahan yang terbuat dari logam yang mampu menghubungkan berbagai komponen elektronik satu sama lain tanpa menggunakan kabel. Tahapan dalam pebuatan PCB sebelum dapat digunakan harus melewati proses pencetakan jalur yang sesuai dengan rangkaian yang diinginkan. Kemudian dilakukan proses penghilangan bagian PCB yang tidak terkena jalur atau proses etching, dan dilanjutkan proses pelubangan pada titiktitik dimana kaki-kaki komponen elektronika akan diletakkan.[1][2]

Pada proses pengeboran PCB dirasa cukup sulit jika dilakukan oleh manusia karena dibutuhkan ketelitian karena ukuran lubang yang kecil. Selain itu, pengeboran juga tidak membutuhkan waktu yang sedikit apalagi dalam sebuah rangkaian yang terdapat banyak jalur kaki untuk masing-masing komponen. Dengan banyaknya teknologi yang berkembang pada saat ini, komputer telah di aplikasikan pada alat-alat mesin perkakas, salah satunya yaitu mesin bor.[3]

Hasil dari perpaduan teknologi komputer dan teknologi mekanik inilah yang kemudian dinamakan dengan (Computer Numerically Controlled). Disebut sebagai CNC, karena proses pergerakan pada mesin mekanik tersebut digerakkan melalui komputer. Komputer membutuhkan bahasa pemrograman G-code agar hardware pada $\mathrm{CNC}$ tersebut agar dapat mengetahui instruksi yang diberikan oleh komputer melalui kode-kode tertentu.[4] Pengelolaan kode dari bentuk gambar ke bentuk G-code memerlukan sebuah converter dalam bentuk format .gcd yang kemudian dapat terbaca dengan baik oleh komputer maupun hardware dari CNC tersebut. Oleh karena itu, untuk menambah tingkat kepresisian dan kemudahan dalam melakukan proses pengeboran pada PCB, maka dirancanglah mesin pengebor otomatis pada PCB menggunakan $\mathrm{CNC}$. 


\section{A. $\mathrm{CNC}$}

\section{TEORI}

CNC (Computer Numerical Control) merupakan suatu mesin yang tergolong dalam mesin perkakas, dikontrol oleh komputer dengan menggunakan bahasa numerik (data perintah dengan kode angka, huruf dan simbol) sesuai dengan standar yang telah disepakati.[7] Sistem kerja dari CNC ini bila dibandingkan dengan mesin perkakas lain, maka perkakas CNC ini bisa dibilang lebih teliti, lebih tepat, lebih fleksibel dan lebih cocok apabila melakukan produksi secara masal. Dengan adanya mesin perkakas ini dapat mempermudah dalam produksi yang membutuhkan tingkat kerumitan yang tinggi, selain itu dalam mesin ini juga pengoperasian sepenuhnya ada pada pengendali utama, jadi tidak banyak campur tangan operator selama mesin ini sedang beroperasi.[8]

Pada mesin CNC terdapat perangkat komputer yang disebut Machine Control Unit (MCU). Mempunyai fungsi menerjemahkan bahasa kode ke dalam bentuk-bentuk gerakan persumbuan sesuai bentuk benda kerja. Kode-kode bahasa dalam mesin perkakas CNC dikenal dengan kode $\mathrm{M}$ dan $\mathrm{G}$, dimana kode-kode tersebut telah distandarkan oleh ISO atau badan Internasional lainnya.[9]

\section{B. Raspberry}

Raspberry pi atau lebih dikenal (RasPi) merupakan sebuah komputer single-board yang dibuat oleh Raspberry foundation di inggris yang bertujuan sebagai sarana edukasi ilmu komputer dasar. Raspberry pi 3 merupakan seri generasi ketiga dari produk raspberry pi dimana pada seri ketiga terdapat built-in wireless dan processor yang lebih baik dari versi raspberry sebelumnya.[10]

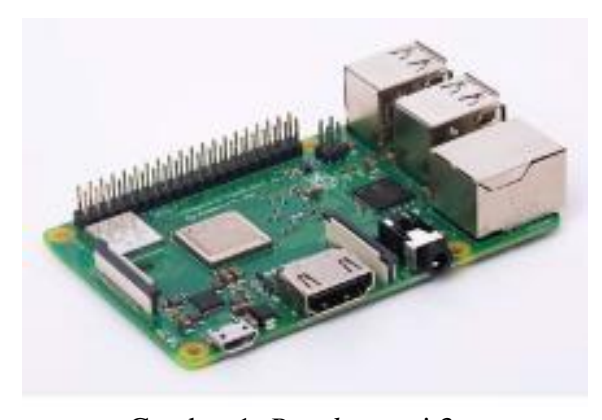

Gambar 1. Raspberry pi 3

Berikut merupakan spesifikasi lengkap dari raspberry pi 3 pada tabel 1 .

Tabel I. Spesifikasi Raspberry

\begin{tabular}{ll}
\hline \multicolumn{1}{c}{ SPESIFIKASI } & \multicolumn{1}{c}{ Raspberry pi 3 } \\
\hline Soc & BCM2837 \\
Processor & $1.2 \mathrm{GHz} 64$-bit quad- \\
& core ARMv8 CPU \\
Memory/RAM & $1 \mathrm{~GB}$ SDRAM \\
& 400MHz \\
GPU & VideoCore IV 3D \\
& graphics LAN \\
\hline
\end{tabular}

\begin{tabular}{ll}
\hline LAN & 802.1 In Wireless \\
& LAN \\
Bluetooth & Bluetooth 4.1 \\
GPIO & 40 Pin \\
Port USB & 4 USB Ports \\
Card Storage & Micro SD card slot \\
Jaringan & Ethernet Port \\
External Audio and & Full HDMI port, \\
Video & Camera Interface \\
& (CSI), Display Inter- \\
& face (DSI), Com- \\
& bined 3.5mm audio \\
& jack and composite \\
& video \\
Debian GNU/Linux, \\
Sistem Operasi & Fedora, Arch Linux \\
& ARM, RISC OS \\
\end{tabular}

\section{Kontrol PID}

Pengendali PID (Proportional, Integral, Derivative) merupakan suatu pengendali yang mampu memperbaiki tingkat akurasi dari suatu sistem plant yang memiliki karakteristik umpan balik/feedback pada sistem tersebut. Pengendali PID menghitung dan meminimalisasi nilai error/selisih antara output dari proses terhadap input/setpoint yang diberikan ke sistem.[11]

Gabungan antara Proportional, Integral, dan Derivative maka disebutlah kontroler PID. Kontrol pada error yang terjadi (Proportional), jumlah error (Integral), dan perubahan error (Derivative) setiap aksi kontrol ini memberikan kontribusi. Steady state dapat dipercepat dengan kombinasi dari 3 kontroler tersebut serta juga mengurangi setting time osilasi sistem itu sendiri. Perbaikan secara signifikan stabilitas yang dinamis dapat diberikan dengan penggunaan self tuning PID pada sistem kontrol. Secara adaptif self tuning merupakan parameter penguat PID. Kontrol PID dapat dipakai secara bersamaa atau sendiri - sendiri tergantung dengan respon yang akan kita inginkan dalam suatu perencanaan.[12]

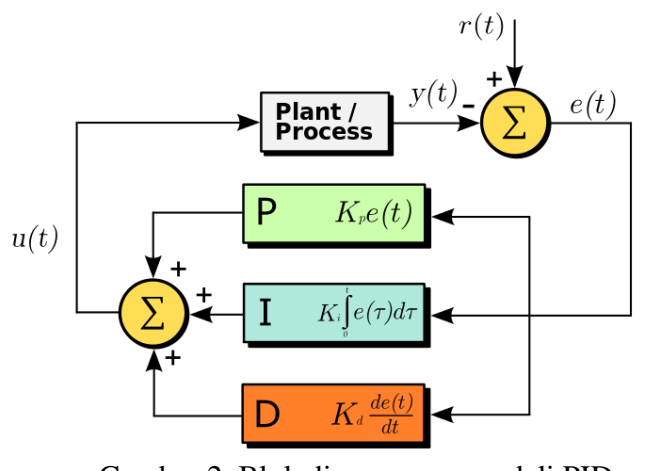

Gambar 2. Blok diagram pengendali PID

Nilai output dari pengendali PID didapatkan berdasarkan penjumlahan dari masing-masing komponennya sebagai berikut:

$$
u(t)=K_{p} e(t)+K_{i} \int_{0}^{t} e(\tau) d \tau+K_{d} \frac{d e(t)}{d t}
$$




\section{CNC Shield}

CNC shield adalah sebuah modul untuk mesin ukir, printer 3d, dan perangkat berbasis CNC lainnya yang terdiri dari beberapa rangkaian elektronika yang berfungsi sebagai modul yang nantinya dipasang diatas microcontroller arduino, CNC shield sendiri mempunyai beberapa pin dan slot sebagai input dan output dari beberapa komponen seperti motor stepper, limit end stop, emergency, dan lain-lain. CNC shield dikendalikan oleh sebuah program pengubah g-code menjadi gerak mekanis pada motor stepper yang terhubung pada $C N C$ shield, salah satunya yaitu software BCNC.[13]

\section{E. Software Fritzing}

Fritzing adalah salah satu dari perangkat lunak gratis yang dapat dipergunakan dengan baik untuk belajar elektronika. Fritzing memberikan fasilitas pengguna untuk melakukan perancangan sistem di breadboard. Ini sangat memudahkan bagi pengguna yang membutuhkan alat bantu perancangan atau dokumentasi pada sistem yang menggunakan breadboard. Fritzing tidak hanya memiliki fitur perancangan pada breadboard sebagai tambahan dari fitur perancangan schematic dan PCB tetapi juga menyediakan tempat untuk melakukan coding (misalnya untuk sistem Arduino).[14] Sehingga Fritzing cukup lengkap untuk mengembangkan sistem prototipe maupun untuk membantu proses belajar.

\section{F. Software BCNC}

$\mathrm{BCNC}$ adalah program untuk mempersiapkan pekerjaan $\mathrm{CNC}$ untuk membuat $\mathrm{PCB}$ pada router $\mathrm{CNC}$. BCNC merupakan software tatap muka pada mesin $\mathrm{CNC}$ yang digunakan untuk melihat proses mesin pada saat beroperasi dan juga dapat mengendalikan seluruh sumbu pada mesin CNC. BCNC dapat mengambil file gerber yang dihasilkan oleh software Fritzing dan menciptakan isolasi routing.[15]

\section{G. Kode Pemrograman G-code}

Dalam pembuatan program CNC yang di dasari dengan sistem komputer. Terdapat program numerik yang berupa kode huruf, kode angka, dan kode simbol. Kode-kode tersebut dirangkai menjadi sebuah program yang bisa di aplikasikan ke dalam mesin CNC. G code adalah kode yang digunakan untuk menulis program mesin CNC. Semua gerakan mesin CNC diatur oleh kode-kode tersebut.[13]

\section{METODE}

Perancangan sistem kontrol CNC pengebor PCB otomatis berbasis raspberry pi ini terdiri dari 2 tahap, yaitu perancangan perangkat keras (hardware) dan perancangan perangkat lunak (software).

\section{A. Hardware}

Sistem perancangan perangkat keras (hardware) pada mesin CNC pengebor PCB otomatis ini menggunakan beberapa komponen, di antaranya yaitu power supply, modul step down, raspberry pi 3, arduino mega, CNC shield, limit switch, motor stepper, driver a4988, driver motor, motor DC. Seluruh komponen tersebut akan ditempatkan pada satu badan mesin CNC yang berukuran panjang $32 \mathrm{~cm}$, lebar $53 \mathrm{~cm}$ dan lebar $49 \mathrm{~cm}$.

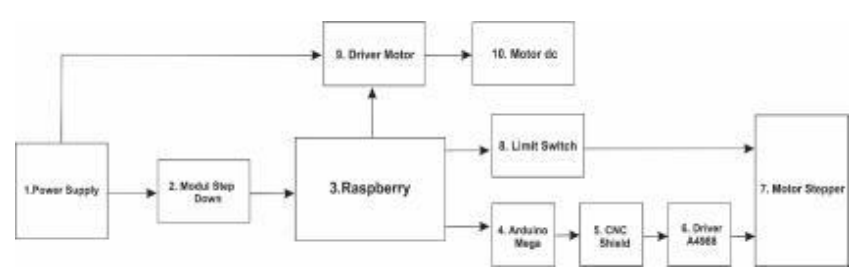

Gambar 3. Diagram koneksi hardware

Koneksi hardware pada alat ini dapat dijelaskan bahwa raspberry merupakan sistem kendali utama. Raspberry mengatur setiap pergerakan yang dilakukan oleh ketiga motor stepper dan satu motor DC. Motor stepper disini berfungsi sebagai penggerak sumbu $\mathrm{x}, \mathrm{y}$ dan z yang bergerak untuk mengarahkan motor DC ke posisi lubang PCB yang akan di bor. Raspberry mengirim perintah kepada motor stepper melalui $C N C$ shield yang terpasang pada arduino mega. Limit switch berfungsi untuk membatasi gerakan pada motor stepper agar tidak bergerak keluar dari bidang kerja yang sudah di tentukan.

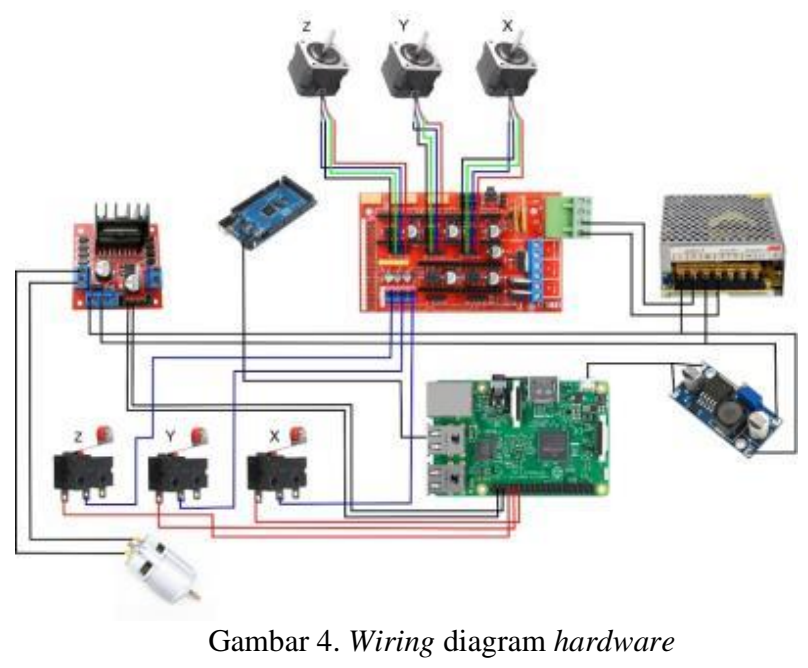

Wiring Diagram Hardware pada gambar 4 dapat dijelaskan bahwa sistem kontrol CNC pengebor PCB otomatis ini menggunakan raspberry pi sebagai otak untuk mengontrol seluruh sistem dari mulai input, output, sampai pengiriman data ke motor stepper dan motor DC. Sumber daya yang dipakai pada rangkaian tersebut menggunakan power supply 12 volt. Power supply disini berfungsi merubah tegangan sumber dari 220 volt AC menjadi 12 volt DC. Kemudian dari power supply tegangan diturunkan kembali menjadi 5 volt oleh modul step down LM5296 sesuai dengan kebutuhan raspberry pi. Raspberry digunakan sebagai input dengan menerima data yang dikirim melalui laptop berupa koordinat lubang pada PCB. Data yang dikirimkan 
berupa gcode agar nantinya bisa terbanya oleh modul CNC. Kemudian data dari raspy dikirimkan ke arduino mega melalui USB serial. Arduino mega terhubung dengan ramps 1.4 yang telah terpasang driver A4988. Driver ini berfungsi menerima dan membaca data sebelumnya untuk kemudian outputnya mengontrol ketiga motor stepper. Ketiga motor stepper masing-masing bekerja terhadap sumbu $\mathrm{x}, \mathrm{y}$ dan $\mathrm{z}$. Tujuan tiga sumbu tersebut untuk memudahkan pergerakan mesin menuju koordinat lubang PCB yang telah di tentukan. Raspberry juga terhubung dengan limit switch yang berfungsi untuk memberi batasan pada motor stepper agar tidak bekerja melewati bidang kerja yang telah ditentukan.

Setelah sumbu $\mathrm{x}$ dan y motor stepper sudah mencapai koordinat lubang, selanjutnya raspberry akan mengirimkan perintah kepada motor DC untuk menggerakkan mata bor. Ketika mata bor berputar, sumbu z dari motor stepper juga akan bekerja untuk menurunkan posisi motor DC agar mata bor dapat melubangi PCB. Fungsi perintah motor DC tersebut dikirimkan melalui port GPIO pada raspberry ke

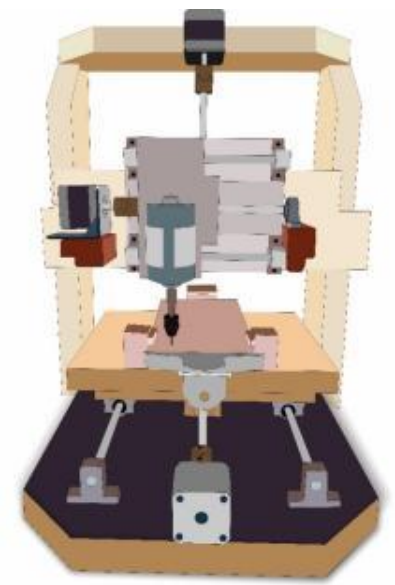

Gambar 5. Desain mekanik mesin CNC tampak depan

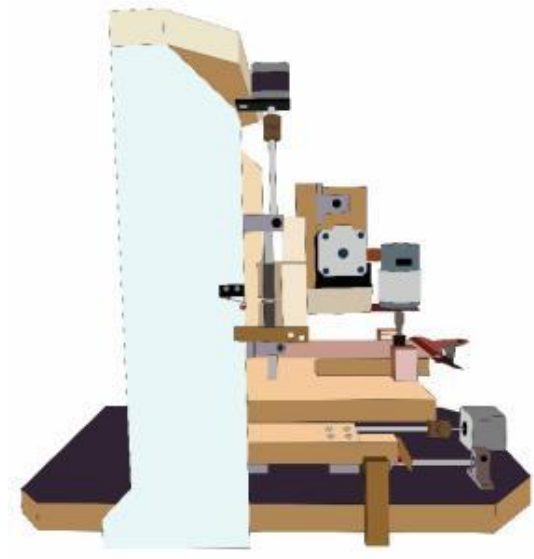

Gambar 6. Desain mekanik mesin CNC tampak samping

Desain perancangan mekanik mesin $\mathrm{CNC}$ ini dapat dilihat pada gambar 5 dan 6 . ukuran alas dari alat ini adalah panjang $32 \mathrm{~cm}$ dan lebar $53 \mathrm{~cm}$. sedangkan tingginya $49 \mathrm{~cm}$. alat ini mempunyai berat $19,5 \mathrm{~kg}$. Alat ini menggunakan kayu sebagai penopang dari setiap komponen yang digunakan. Menggunakan kayu yang cukup tebal dan kuat bertujuan untuk menjaga kestabilan setiap komponen agar lebih tahan terhadap getaran maupun goncangan. Tujuan lain dari penggunaan kayu ini adalah untuk menghindari adanya arus bocor sehingga tidak membahayakan pengguna. Alat ini telah di desain sebaik mungkin, seminimalis mungkin untuk menempatkan berbagai komponen mekanik maupun elektronikanya.

\section{B. Software}

Di dalam perancangan software alat ini terdapat 5 software yang dijalankan, antara lain: Fritzing, Copper CAM, PCB Designer, Python dan BCNC.

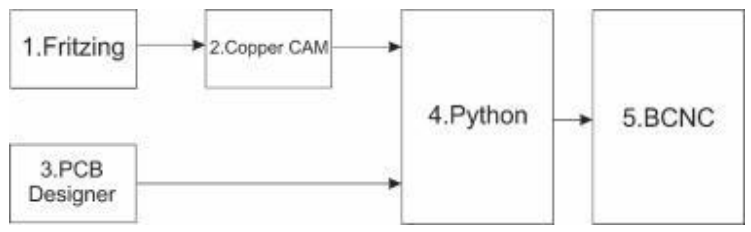

Gambar 5. Diagram koneksi software

Sistem perancangan perangkat lunak (software) pada mesin CNC pengebor PCB otomatis ini menggunakan aplikasi Fritzing dan PCB designer sebagai input yang digunakan untuk membuat skematik rangkaian pada PCB sekaligus mengkonversinya menjadi kode G. Kemudian hasil dari kode-kode tersebut di pindah pada aplikasi pemrograman raspberry yaitu phyton agar bisa terbaca oleh BCNC. Lalu di import ke aplikasi BCNC sebagai aplikasi tatap muka untuk mesin CNC. BCNC digunakan untuk membaca koordinat setiap lubang dan mengontrol setiap pergerakan sumbu pada mesin CNC.

\section{Flowchart Sistem}

Berikut flowchart sistem kerja dari mesin CNC dapat dijelaskan bahwa hal pertama yang dilakukan adalah pembuatan skematik rangkaian $\mathrm{PCB}$, kemudian dikonversi menjadi kode $\mathrm{G}$ untuk setiap lubang. Lalu penginputan koordinat lubang pada layout PCB yang telah dibuat. Penginputan ini dilakukan dengan cara mengkonversi desain layout PCB yang telah dibuat kedalam bentuk bahasa pemrograman gcode. Hal ini dilakukan agar koordinat lubang dapat terbaca oleh mesin CNC. Kemudian data koordinat lubang akan dikirimkan ke raspberry untuk dibaca dan diolah. Raspberry akan mengirimkan perintah kepada tiap motor melalui $C N C$ shield yang terpasang ke arduino. Setiap motor akan bekerja sesuai dengan rule base yang telah ditentukan secara otomatis. 


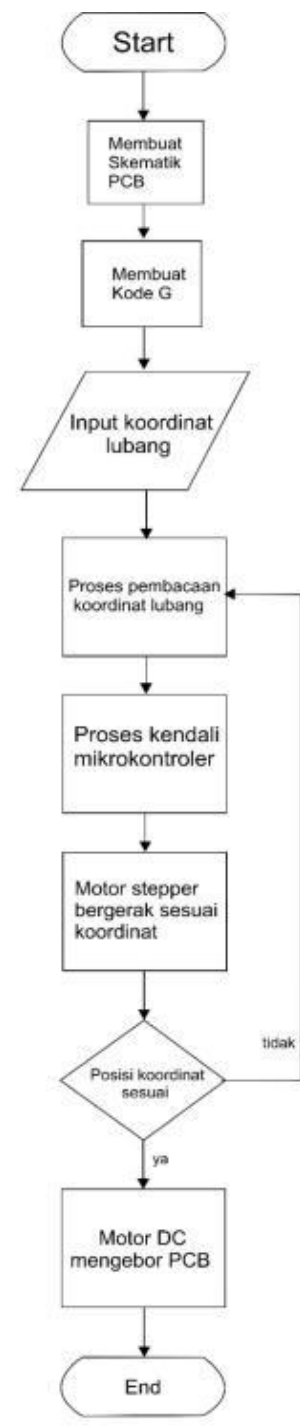

Gambar 7. Flowchart sistem kerja pada mesin CNC

\section{HASIL DAN PEMBAHASAN}

Pada penelitian ini diharapkan sistem dapat beroperasi dengan lancar, baik dari hardware maupun software. Diharapkan mesin dapat membaca setiap koordinat lubang pada layout PCB yang telah dibuat pada software fritzing. Dengan begitu ketiga sumbu yang digerakkan oleh motor stepper dapat berjalan sesuai dengan koordinat lubang yang dituju.

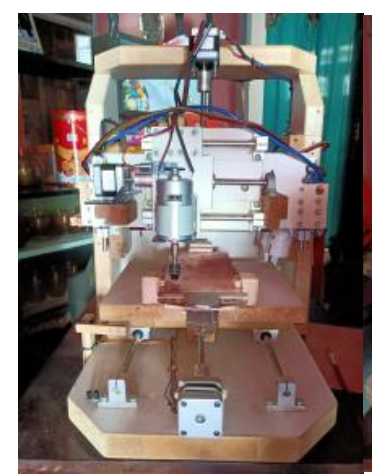

(a)

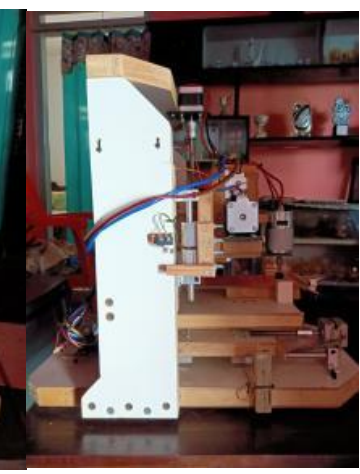

(b)
Gambar 8. (a) Mekanik CNC tampak depan (b) Mekanik CNC tampak samping

\section{A. Pengujian Interface Melalui BCNC}

Pengujian akurasi ini dilakukan dengan menjalankan mesin CNC dengan jarak $5 \mathrm{~mm}$ dan $10 \mathrm{~mm}$, pada komputer dan melihat reaksi dari mesin CNC dengan menggunakan spidol sebagai penanda. Pengujian ini dilakukan 6 arah pada mesin CNC. Keenam arah tersebut yaitu sumbu $\mathrm{X}+$, sumbu $\mathrm{X}$-, sumbu $\mathrm{Y}+$, sumbu $\mathrm{Y}$-, sumbu Z+, sumbu Z-.

Setelah mesin CNC berjalan sesuai dengan jarak yang ditentukan pada software, maka pergerakan dari motor stepper akan berhenti. Pengujian ini dilakukan dengan cara memberikan spidol yang ditempelkan pada motor dc sebagai penanda berapa jarak yang ditempuh oleh motor stepper. Seperti yang terlihat pada gambar 4.7.

Jarak yang ditempuh motor stepper ini dilakukan sebanyak 10 kali percobaan. Proses tersebut dilakukan pada keenam sumbu. Sumbu X+ bergerak dari titik awal ke kanan. Sumbu X- bergerak dari titik awal ke kiri. Sumbu Y+ bergerak dari titik awal ke arah atas. Sumbu Y- bergerak dari titik awal ke arah bawah. Sumbu Z+ bergerak dari bawah ke atas. Dan sumbu Z- bergerak dari atas ke bawah. Berikut merupakan hasil pengujian yang telah dilakukan.

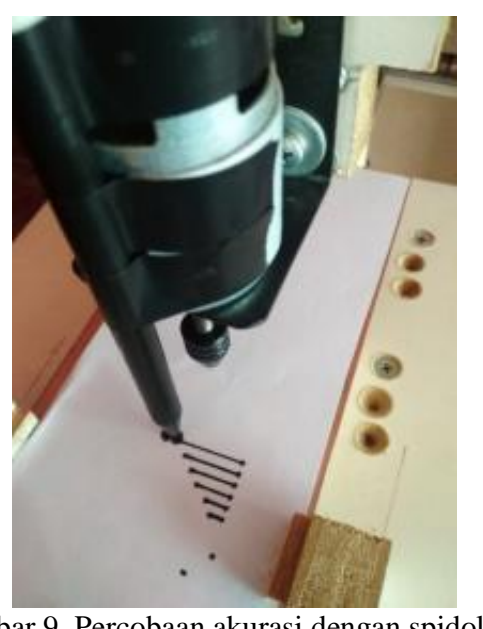

Gambar 9. Percobaan akurasi dengan spidol

\section{1) Sumbu $X$ -}

Tabel II. Data hasil pengukuran sumbu x- sejauh 5mm

\begin{tabular}{ccc}
\hline $\begin{array}{c}\text { Hasil pengukuran } \\
(\mathrm{mm})\end{array}$ & Akurasi $(\%)$ & Error $(\%)$ \\
\hline 5,1 & 99 & 1,00 \\
\hline 5,1 & 99 & 1,00 \\
\hline 5,1 & 99 & 1,00 \\
\hline 5,2 & 98 & 2,00 \\
\hline 5,4 & 96 & 4,00 \\
\hline 5,1 & 99 & 1,00 \\
\hline 5,1 & 99 & 1,00 \\
\hline 4,9 & 99 & 1,00 \\
\hline 5,1 & 99 & 1,00 \\
\hline 5,2 & 98 & 2,00 \\
\hline & Rata-rata & 1,5
\end{tabular}

Tabel III. Data hasil pengukuran sumbu x- sejauh $10 \mathrm{~mm}$

\begin{tabular}{ccc}
\hline \hline $\begin{array}{c}\text { Hasil pengukuran } \\
(\mathrm{mm})\end{array}$ & Akurasi (\%) & Error (\%) \\
\hline 10,2 & 98 & 2,00 \\
\hline 10,1 & 99 & 1,00 \\
\hline
\end{tabular}




\begin{tabular}{ccc}
\hline \hline 10,1 & 99 & 1,00 \\
\hline 10 & 100 & 0,00 \\
\hline 10,5 & 95 & 5,00 \\
\hline 10,1 & 99 & 1,00 \\
\hline 10,1 & 99 & 1,00 \\
\hline 10,2 & 98 & 2,00 \\
\hline 10,5 & 95 & 5,00 \\
\hline 10,4 & 96 & 4,00 \\
\hline & Rata-rata & 2.2 \\
\hline \hline
\end{tabular}

\section{2) Sumbu $X+$}

Tabel IV. Data hasil pengukuran sumbu $\mathrm{x}+$ sejauh $5 \mathrm{~mm}$ Hasil pengukuran Akurasi (\%) Error (\%)

\begin{tabular}{ccc}
$(\mathrm{mm})$ & & \\
\hline 5.1 & 99 & 1,00 \\
\hline 5.1 & 99 & 1,00 \\
\hline 5.5 & 95 & 5,00 \\
\hline 5.1 & 99 & 1,00 \\
\hline 5.1 & 99 & 1,00 \\
\hline 5.2 & 98 & 2,00 \\
\hline 5.1 & 99 & 1,00 \\
\hline 5.1 & 99 & 1,00 \\
\hline 5 & 100 & 0,00 \\
\hline 4.9 & 99 & 1,00 \\
\hline & Rata-rata & 1,4 \\
\hline
\end{tabular}

Tabel V. Data hasil pengukuran sumbu $\mathrm{x}+$ sejauh $10 \mathrm{~mm}$ $\begin{array}{lll}\text { Hasil pengukuran } & \text { Akurasi (\%) } & \text { Error (\%) }\end{array}$

\begin{tabular}{ccc}
$(\mathrm{mm})$ & & \\
\hline 10,1 & 99 & 1,00 \\
\hline 10,4 & 96 & 4,00 \\
\hline 10,2 & 98 & 2,00 \\
\hline 10,1 & 99 & 1,00 \\
\hline 10,2 & 98 & 2,00 \\
\hline 10,2 & 98 & 2,00 \\
\hline 10,1 & 99 & 1,00 \\
\hline 10 & 100 & 0,00 \\
\hline 10,6 & 94 & 6,00 \\
\hline 10,1 & 99 & 1,00 \\
\hline & Rata-rata \\
\hline \hline
\end{tabular}

\section{3) Sumbu $Y$ -}

Tabel VI. Data hasil pengukuran sumbu y- sejauh $5 \mathrm{~mm}$ Hasil pengukuran Akurasi (\%) Error $(\%)$

\begin{tabular}{ccc}
$\begin{array}{c}(\mathrm{mm}) \\
5.2\end{array}$ & 98 & 2,00 \\
\hline 5.5 & 95 & 5,00 \\
\hline 5.2 & 98 & 2,00 \\
\hline 5 & 100 & 0,00 \\
\hline 5 & 100 & 0,00 \\
\hline 5.1 & 99 & 1,00 \\
\hline 4.7 & 97 & 3,00 \\
\hline 4.9 & 99 & 1,00 \\
\hline 5.1 & 99 & 1,00 \\
\hline 5.2 & 98 & 2,00 \\
\hline & Rata-rata & 1,7 \\
\hline \hline
\end{tabular}

Tabel VII. Data hasil pengukuran sumbu y- sejauh $10 \mathrm{~mm}$ Hasil pengukuran Akurasi (\%) Error $(\%)$

\begin{tabular}{ccc}
$(\mathrm{mm})$ & 98 & \\
\hline 10,2 & 99 & 2,00 \\
\hline 10,1 & 99 & 1,00 \\
\hline 10,1 & 95 & 1,00 \\
\hline 10,5 & 97 & 5,00 \\
\hline 9,7 & 99 & 3,00 \\
\hline 9,9 & 97 & 1,00 \\
\hline 10,3 & 100 & 3,00 \\
\hline 10 & 95 & 1,00 \\
\hline 10,5 & 99 & 5,00 \\
\hline 10,1 & & 1,00 \\
\hline
\end{tabular}

Rata-rata

\section{4) Sumbu Y+}

Tabel VIII. Data hasil pengukuran sumbu y+ sejauh $5 \mathrm{~mm}$

\begin{tabular}{ccc}
\hline $\begin{array}{c}\text { Hasil pengukuran } \\
(\mathrm{mm})\end{array}$ & Akurasi (\%) & Error (\%) \\
\hline 5 & 100 & 0,00 \\
\hline 5.1 & 99 & 1,00 \\
\hline 5.1 & 99 & 1,00 \\
\hline 4.9 & 99 & 1,00 \\
\hline 4.8 & 98 & 2,00 \\
\hline 5 & 100 & 0,00 \\
\hline 5 & 100 & 0,00 \\
\hline 5.1 & 99 & 1,00 \\
\hline 4.9 & 99 & 1,00 \\
\hline 4.9 & 99 & 1,00 \\
\hline & Rata-rata & 0,8 \\
\hline
\end{tabular}

Tabel IX. Data hasil pengukuran sumbu y+ sejauh $10 \mathrm{~mm}$ $\begin{array}{lll}\text { Hasil pengukuran } & \text { Akurasi (\%) } & \text { Error (\%) }\end{array}$

\begin{tabular}{ccc}
$(\mathrm{mm})$ & & \\
\hline 10 & 100 & 0,00 \\
\hline 10,1 & 99 & 1,00 \\
\hline 10,1 & 99 & 1,00 \\
\hline 10,2 & 98 & 2,00 \\
\hline 10,5 & 95 & 5,00 \\
\hline 10,6 & 94 & 6,00 \\
\hline 10,4 & 96 & 4,00 \\
\hline 10,1 & 99 & 1,00 \\
\hline 10,1 & 99 & 1,00 \\
\hline 9,8 & 98 & 2,00 \\
\hline & Rata-rata & 2,3 \\
\hline \hline
\end{tabular}

\section{5) Sumbu Z-}

Tabel X. Data hasil pengukuran sumbu z- sejauh $5 \mathrm{~mm}$ $\begin{array}{lll}\text { Hasil pengukuran } & \text { Akurasi (\%) } & \text { Error (\%) }\end{array}$

\begin{tabular}{ccc}
$(\mathrm{mm})$ & & \\
\hline 5 & 100 & 0,00 \\
\hline 5 & 100 & 0,00 \\
\hline 5 & 100 & 0,00 \\
\hline 5 & 100 & 0,00 \\
\hline 5 & 100 & 0,00 \\
\hline 5 & 100 & 0,00 \\
\hline 5.1 & 99 & 1,00 \\
\hline 5 & 100 & 0,00 \\
\hline 5.1 & 99 & 1,00 \\
\hline 5 & 100 & 0,00 \\
\hline & Rata-rata & 0,2 \\
\hline \hline
\end{tabular}

Tabel XI. Data hasil pengukuran sumbu z- sejauh 10mm $\begin{array}{lll}\text { Hasil pengukuran } & \text { Akurasi (\%) } & \text { Error (\%) }\end{array}$

\begin{tabular}{ccc}
$(\mathrm{mm})$ & & \\
\hline 10 & 100 & 0,00 \\
\hline 10 & 100 & 0,00 \\
\hline 10 & 100 & 0,00 \\
\hline 10 & 100 & 0,00 \\
\hline 10,1 & 99 & 1,00 \\
\hline 10 & 100 & 0,00 \\
\hline 10,2 & 98 & 2,00 \\
\hline 10 & 100 & 0,00 \\
\hline 10 & 100 & 0,00 \\
\hline 10,1 & 99 & 1,00 \\
\hline & Rata-rata & 0,4 \\
\hline \hline
\end{tabular}


6) Sumbu Z+

Tabel XII. Data hasil pengukuran sumbu z+ sejauh $5 \mathrm{~mm}$

\begin{tabular}{ccc}
\hline $\begin{array}{c}\text { Hasil pengukuran } \\
(\mathrm{mm})\end{array}$ & Akurasi $(\%)$ & Error $(\%)$ \\
\hline 5 & 100 & 0,00 \\
\hline 5 & 100 & 0,00 \\
\hline 5 & 100 & 0,00 \\
\hline 5,1 & 99 & 1,00 \\
\hline 5 & 100 & 0,00 \\
\hline 5 & 100 & 0,00 \\
\hline 5.1 & 99 & 1,00 \\
\hline 5 & 100 & 0,00 \\
\hline 5 & 100 & 0,00 \\
\hline 5 & 100 & 0,00 \\
\hline & Rata-rata & 0,2 \\
\hline \hline
\end{tabular}

Tabel XIII. Data hasil pengukuran sumbu z+ sejauh 10mm

\begin{tabular}{ccc}
\hline \hline $\begin{array}{c}\text { Hasil pengukuran } \\
(\mathrm{mm})\end{array}$ & Akurasi $(\%)$ & Error $(\%)$ \\
\hline 10 & 100 & 0,00 \\
\hline 10,2 & 98 & 2,00 \\
\hline 10 & 100 & 0,00 \\
\hline 10 & 100 & 0,00 \\
\hline 10 & 100 & 0,00 \\
\hline 10 & 100 & 0,00 \\
\hline 10,1 & 99 & 1,00 \\
\hline 10,1 & 99 & 1,00 \\
\hline 10 & 100 & 0,00 \\
\hline 10 & 100 & 0,00 \\
\hline & Rata-rata & 0,4 \\
\hline \hline
\end{tabular}

Dari seluruh percobaan setiap sumbu dengan masing-masing dilakukan sepuluh kali percobaan, maka dapat di rata-rata sehingga menghasilkan nilai keakuratan dari nilai error tersebut. Berikut perhitungan nilai error rata-rata dari seluruh percobaan:

$$
\text { error }=\frac{\text { jumlah_seluruh_rata }- \text { rata_error }}{\text { banyak_pengukuran }} \times 100
$$

Jadi untuk menghitung error dari seluruh data adalah:

$$
\text { error }=\frac{15,4}{12} x 100=1,2 \%
$$

Jadi dari pengukuran di atas data yang diperoleh menunjukkan mesin CNC pengebor PCB otomatis ini memiliki akurasi jarak sebesar 98,8\% dengan nilai error yang dihasilkan sebesar 1,2\%.

\section{B. Pengujian Pengeboran Pada Layout \\ 1) Rangkaian Pertama}

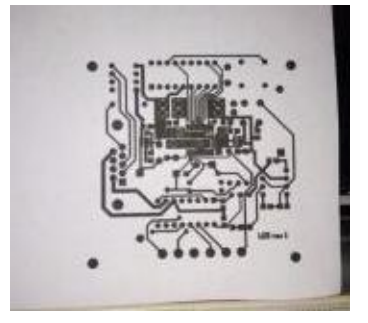

(a)

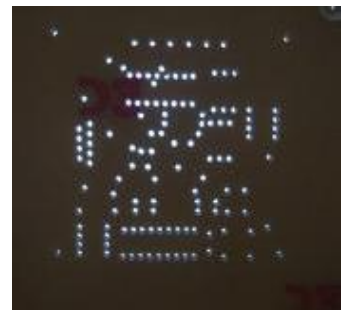

(b)
Gambar 10. (a) Layout sebelum di bor (b) PCB setelah di bor
Pada gambar 10 merupakan rangkain yang telah dibuat dan merupakan hasil dari proses pengeboran yang telah dilakukan. Dapat dilihat banyak lubang yang ada pada rangkaian tersebut sebanyak 131 . Proses pengeboran pada percobaan pertama ini berjalan dengan lancar dan proses pengeboran sudah tepat sesuai dengan titik yang telah disediakan.

Proses pengeboran pada rangkian ini dilakukan sebanyak tiga kali. Setelah dilakukan proses pengeboran sebanyak tiga kali.

Tabel XIV. Data pengeboran rangkaian pertama

\begin{tabular}{cccccc}
\hline \hline No & $\begin{array}{c}\text { Banyak } \\
\text { Lubang }\end{array}$ & Terbor & Meleset & $\begin{array}{c}\text { Tidak } \\
\text { Terbor }\end{array}$ & \\
& & $1 \%)$ & \\
1 & 131 & 131 & 0 & 0 & $100 \%$ \\
2 & 131 & 131 & 3 & 0 & $97.7 \%$ \\
3 & 131 & 131 & 2 & 0 & $98.5 \%$ \\
\hline \hline
\end{tabular}

\section{2) Rangkaian Kedua}

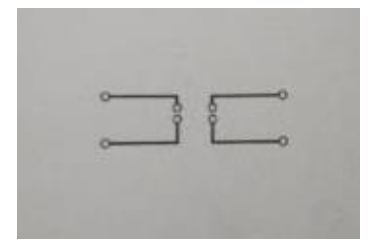

(a)

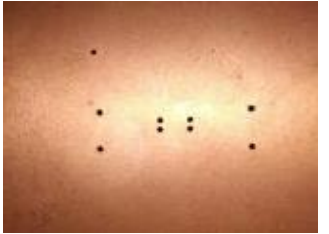

(b)
Gambar 11. (a) Layout sebelum di bor (b) PCB setelah di bor

Pada gambar 11 merupakan hasil dari percobaan kedua yang telah dilakukan, dan dapat dilihat banyak lubang yang ada pada rangkaian tersebut sebanyak 8 lubang. Pada percobaan kedua ini lubang yang berhasil di bor sebanyak 8 dan tidak ada satupun mata bor yang meleset pada lubang. Proses pengeboran sudah tepat sesuai dengan titik yang telah disediakan.

Tabel XV. Data pengeboran rangkaian kedua

\begin{tabular}{cccccc}
\multicolumn{6}{c}{ Tabel XV. Data pengeboran rangkaian kedua } \\
\hline \hline No & $\begin{array}{c}\text { Banyak } \\
\text { Lubang }\end{array}$ & Terbor & Keterangan & $\begin{array}{c}\text { Ketepatan } \\
(\%)\end{array}$ \\
& & 8 & 0 & $\begin{array}{c}\text { Tidak } \\
\text { Terbor }\end{array}$ \\
1 & 8 & 8 & 0 & 0 & $100 \%$ \\
3 & 8 & 8 & 0 & 0 & $100 \%$ \\
\hline \hline
\end{tabular}

\section{3) Rangkaian Ketiga}

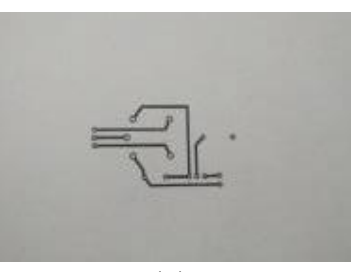

(a)

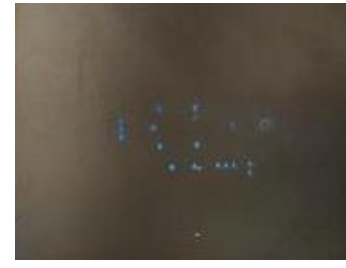

(b)
Gambar 12. (a) Layout sebelum di bor (b) PCB setelah di bor

Pada gambar 12 merupakan hasil dari percobaan 
ketiga yang telah dilakukan, dan dapat dilihat banyak lubang yang ada pada rangkaian tersebut sebanyak 17 lubang. Pada percobaan ketiga ini lubang yang berhasil di bor sebanyak 17 dan tidak ada satupun mata bor yang meleset pada lubang. Proses pengeboran sudah tepat sesuai dengan titik yang telah disediakan.

\begin{tabular}{|c|c|c|c|c|c|}
\hline \multirow[t]{2}{*}{ No } & \multirow{2}{*}{$\begin{array}{l}\text { Banyak } \\
\text { Lubang }\end{array}$} & \multicolumn{3}{|c|}{ Keterangan } & \multirow[t]{2}{*}{$\begin{array}{c}\text { Ketepatan } \\
(\%)\end{array}$} \\
\hline & & Terbor & Meleset & $\begin{array}{l}\text { Tidak } \\
\text { Terbor }\end{array}$ & \\
\hline 1 & 17 & 17 & 0 & 0 & $100 \%$ \\
\hline 2 & 17 & 17 & 0 & 0 & $100 \%$ \\
\hline 3 & 17 & 17 & 0 & 0 & $100 \%$ \\
\hline
\end{tabular}

\section{Pengujian PID}

Kontrol PID merupakan kontrol yang memiliki stabilitas yang baik dengan tingkat error dan overshoot yang kecil. Tujuan dari penggunaan PID pada alat ini adalah untuk membuat putaran motor DC lebih stabil. Karena kecepatan putaran motor DC sering tidak stabil akibat gangguan dari luar maupun perubahan parameter dari fabrikasinya. Agar diperoleh pengontrol yang baik maka dilakukan tuning parameter pengontrol proporsional (Kp), Intergral (Ki) dan Derivatif (Kd).[16]

Untuk mendapat nilai respon controller yang optimal dapat dilakukan dengan pemilihan harga koefisien pada Kp, Ki dan Kd, dengan menggunakan metode auto tuning. Metode ini menghasilkan respon sinyal lebih baik daripada menggunakan metode traditional tuning.

Sistem mengendalikan dan mengatur kecepatan motor dengan teknik Pulse Width Modulation (PWM). Pengontrol mengeluarkan sinyal PWM ke driver untuk menguatkan arus. Sinyal PWM yang sudah dikuatkan arusnya digunakan untuk menggerakkan motor DC dengan level 0-255. Motor DC yang digunakan merupakan motor 6-36 VDC dengan RPM maksimal tanpa beban 12000 yang merupakan motor DC magnet permanen.

Auto tuning dilakukan dengan menggunakan software Matlab dengan menggunakan simulasi pada fitur matlab yaitu simulink. Sebelum proses simulasi dimulai hal pertama yang dilakukan adalah mengetahui parameter-parameter pada motor DC. Berikut merupakan parameter pada motor DC:

\begin{tabular}{ll}
\multicolumn{2}{c}{ Tabel XVII. Parameter motor dc } \\
\hline \hline \multicolumn{1}{c}{ Keterangan } & \multicolumn{1}{c}{ Nilai } \\
\hline Momen inersia rotor $(\mathrm{J})$ & $0,18 \mathrm{~kg} / \mathrm{m}^{2}$ \\
rasio peredaman sistem mekanik (b) & $0,0055 \mathrm{Nms}$ core \\
Konstanta gaya elektronik $(\mathrm{Kt})$ & $0,01 \mathrm{Nm} / \mathrm{Amp}$ \\
Tahanan elektrik (R) & $6.25 \mathrm{ohm}$ \\
Induktansi elektrik (L) & $0,024 \mathrm{H}$ \\
konstanta tahanan elektrik $(\mathrm{Ke})$ & $1 \mathrm{~V} / \mathrm{Rad} / \mathrm{Sec}$ \\
\hline \hline
\end{tabular}

Kemudian nilai-nilai tersebut akan dihitung untuk mendapatkan nilai transfer function. Berikut rumus transfer function pada motor DC:

$$
\frac{K t}{(L x J) s^{2}+(L x b+R x J)+(R x b+K t x K e)}
$$

Mencari konstanta PID memerlukan beberapa tahapan pada saat menggunakan simulasi simulink pada Mathlab. Berikut tahapan-tahapan dalam mencari nilai $\mathrm{Kp}, \mathrm{Ki}$ dan $\mathrm{Kd}$ :

a) Carilah nilai transfer function dari rumus diatas secara otomatis menggunakan mathlab.

b) Setelah mendapatkan nilai transfer function, Langkah selanjutnya adalah membuka simulink pada Matlab dan membuat rangkaian simulasi untuk mengetahui nilai rise time dari motor DC. berikut rangkaian simulasi pada simulink:

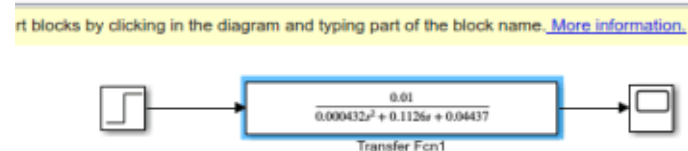

Gambar 13. Rangkaian simulasi pada simulink

Setelah rangkaian selesai dan nilai dari transfer function sudah diinputkan, lalu klik run. Kemudian klik pada scope untuk mengetahui grafik sinyal dan rise time yang dihasilkan.

c) Hasil dari sinyal tersebut menunjukkan nilai rise time yang dihasilkan sebesar 5.071 detik. Nilai tersebut tentu sangat besar karena waktu yang diperlukan untuk naik sampai dengan respon memotong sumbu pertama bernilai 5 detik.

Hasil dari rise time tersebut akan dipercepat dengan nilai dibawah satu detik agar respon sistem lebih cepat stabil. Cara yang dilakukan agar nilai rise time bisa dipercepat adalah dengan menggunakan kontrol PID dengan tujuan untuk menentukan presisi pada suatu sistem instrumentasi. Dengan menggunakan PID, plant yang sebelumnya menggunakan sistem lingkar terbuka (open loop) kemudian akan menjadi sistem lingkar tertutup (close loop). Seperti terlihat pada gambar berikut ini:

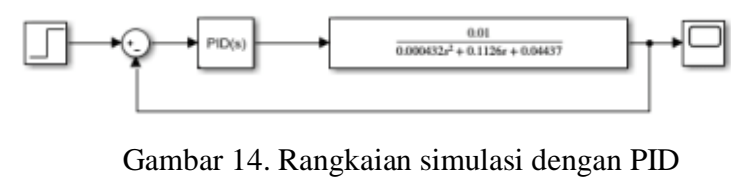

d) Setelah rangkaian selesai dengan penambahan PID, kemudian gunakan fitur dari Matlab untuk mengatur respon sistem yang kita inginkan. Fitur ini juga untuk mengetahui berapa nilai $\mathrm{Kp}, \mathrm{Ki}$ dan Kd yang didapatkan dari respon sistem tersebut. Fitur ini bernama PID tuner. 
e) Setelah itu kita atur nilai rise time untuk mendapat nilai dibawah satu detik. Jangan lupa untuk memperhatikan nilai overshoot agar tidak terlalu besar. Dengan memperhatikan kedua nilai tersebut maka nilai respon (settling time) juga akan semakin cepat berada pada keadaan steady state. Kita dapat mengatur nilai-nilai tersebut dengan menggunakan menu tuning tools pada PID tuner.

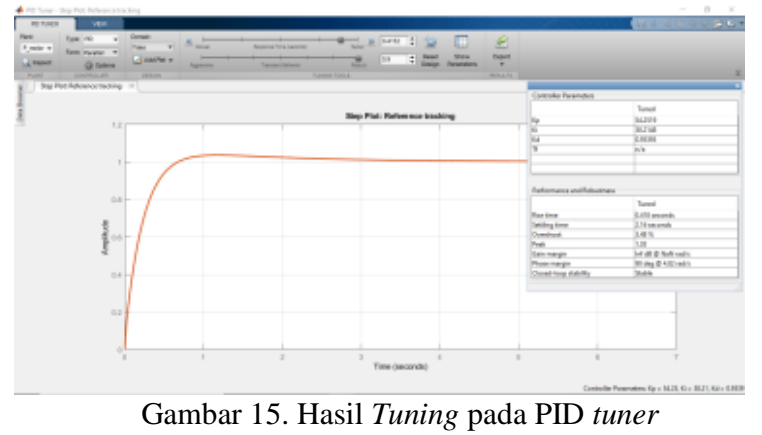

f) Setelah diatur dengan menggunakan tuning tools, Dapat dilihat pada gambar 4.35 bahwa nilai rise time yang didapat adalah 0,418 detik. Dengan nilai overshoot sebesar $3,48 \%$ dan nilai settling time sebesar 2,16 detik. Setelah respon sistem sesuai dengan yang diinginkan, maka nilai kontrol parameter $\mathrm{Kp}$, Ki dan Kd akan otomatis didapat seperti pada gambar diatas. Nilai PID yang didapat adalah $\mathrm{Kp}=54, \mathrm{Ki}=38$ dan $\mathrm{Kd}=$ 0.9. setelah mendapat nilai $\mathrm{Kp}, \mathrm{Ki}$ dan $\mathrm{Kd}$ kemudian nilai tersebut kita masukkan pada PID yang terdapat pada simulink. Lalu run dan klik scope untuk melihat respon sinyalnya.

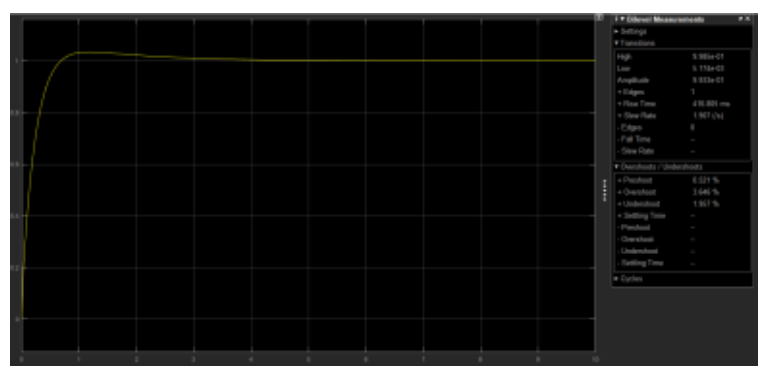

Gambar 16. Diagram Sinyal Dengan PID

g) Dari gambar 16 dapat dilihat bahwa rise time yang dihasilkan setelah menggunakan PID adalah $416 \mathrm{~ms}$ atau sekitar 0,4 detik. Dengan nilai sebelumnya yang mencapai 5 detik tanpa menggunakan PID. Dari sinyal tersebut dapat dilihat jika dengan menggunakan PID respon sistem lebih cepat dan lebih stabil dengan waktu yang lebih singkat untuk mencapai steady state.

Dengan menggunakan auto tuning tersebut didapat nilai parameter motor DC yang optimal yaitu $\mathrm{Kp}=54, \mathrm{Ki}=38$ dan $\mathrm{Kd}=0.9$. Dari nilai tersebut didapat nilai PWM yang stabil dengan nilai yang mendekati setpoint.
Tabel XVIII. Data pengujian PID

\begin{tabular}{|c|c|c|c|}
\hline No & setpoint & $54,38,0.9$ & RPM \\
\hline 1 & 225 & 223.975 & 6.150 \\
\hline 2 & 225 & 223.975 & 6.150 \\
\hline 3 & 225 & 224.9001298 & 6.200 \\
\hline 4 & 225 & 224.9001298 & 6.200 \\
\hline 5 & 225 & 224.9001298 & 6.200 \\
\hline 6 & 225 & 224.9001298 & 6.200 \\
\hline 7 & 225 & 224.9001298 & 6.200 \\
\hline 8 & 225 & 230.8501023 & 6.335 \\
\hline 9 & 225 & 230.8501023 & 6.335 \\
\hline 10 & 225 & 230.8501023 & 6.335 \\
\hline 11 & 225 & 230.8501023 & 6.335 \\
\hline 12 & 225 & 230.8501023 & 6.335 \\
\hline 13 & 225 & 222.9747852 & 6.100 \\
\hline 14 & 225 & 222.9747852 & 6.100 \\
\hline 15 & 225 & 222.9747852 & 6.100 \\
\hline 16 & 225 & 222.9747852 & 6.100 \\
\hline 17 & 225 & 222.9747852 & 6.100 \\
\hline 18 & 225 & 222.9250994 & 6.100 \\
\hline 19 & 225 & 222.9250994 & 6.100 \\
\hline 20 & 225 & 222.9250994 & 6.100 \\
\hline 21 & 225 & 222.9250994 & 6.100 \\
\hline 22 & 225 & 222.9250994 & 6.100 \\
\hline 23 & 225 & 220.9749263 & 6.080 \\
\hline 24 & 225 & 220.9749263 & 6.080 \\
\hline 25 & 225 & 220.9749263 & 6.080 \\
\hline 26 & 225 & 220.9749263 & 6.080 \\
\hline 27 & 225 & 222.9500649 & 6.100 \\
\hline 28 & 225 & 222.9500649 & 6.100 \\
\hline 29 & 225 & 222.9500649 & 6.100 \\
\hline 30 & 225 & 222.9500649 & 6.100 \\
\hline 31 & 225 & 228.8751335 & 6.300 \\
\hline 32 & 225 & 228.8751335 & 6.300 \\
\hline 33 & 225 & 228.8751335 & 6.300 \\
\hline 34 & 225 & 228.8751335 & 6.300 \\
\hline 35 & 225 & 226.8999963 & 6.250 \\
\hline 36 & 225 & 226.8999963 & 6.250 \\
\hline 37 & 225 & 226.8999963 & 6.250 \\
\hline 38 & 225 & 224.9249898 & 6.150 \\
\hline 39 & 225 & 224.9249898 & 6.150 \\
\hline 40 & 225 & 224.9249898 & 6.150 \\
\hline 41 & 225 & 224.9249898 & 6.150 \\
\hline 42 & 225 & 222.9500024 & 6.100 \\
\hline 43 & 225 & 222.9500024 & 6.100 \\
\hline 44 & 225 & 222.9500024 & 6.100 \\
\hline 45 & 225 & 227.9001334 & 6.250 \\
\hline 46 & 225 & 227.9001334 & 6.250 \\
\hline 47 & 225 & 227.9001334 & 6.250 \\
\hline 48 & 225 & 222.9749072 & 6.100 \\
\hline 49 & 225 & 222.9749072 & 6.100 \\
\hline 50 & 225 & 222.9749072 & 6.100 \\
\hline
\end{tabular}




\section{KESIMPULAN}

Berdasarkan proses implementasi, pengujian dan analisis yang dilakukan, maka dapat disimpulkan bahwa mesin CNC pengebor PCB otomatis berbasis raspberry dapat direalisasikan sesuai dengan perancangan awal hardware maupun software. Penentuan koordinat lubang pada skematik yang dibuat dilakukan dengan mengkonversi layout yang telah dibuat ke dalam kode pemrograman yang disebut gcode. Implementasi PID untuk motor DC berdasarkan metode auto tuning didapatkan nilai konstanta $\mathrm{Kp}=54, \mathrm{Ki}=38$ dan $\mathrm{Kd}=$ 0.9. Pengujian ketelitian pada sumbu $\mathrm{x}-, \mathrm{x}+, \mathrm{y}-, \mathrm{y}+, \mathrm{z}-$ dan $\mathrm{z}+$ dilakukan masing-masing sepuluh kali percobaan dengan tingkat akurasi keseluruhan $98,8 \%$.

Untuk penelitian selanjutnya agar mesin lebih optimal, tidak hanya diperlukan rangkaian elektronika yang stabil. Tetapi juga membutuhkan pengujian mekanik lebih maksimal dari segi kekuatan, ketahanan dan kestabilan. Dikarenakan mesin CNC akan bekerja maksimal jika suatu mekanik CNC tersebut mempunyai kualitas yang sangat bagus. Untuk penempatan PCB yang akan di bor dapat digunakan suatu pengolahan citra digital yang nantinya akan mendukung letak koordinat suatu PCB secara bebas sehingga tidak perlu memposisikan terlebih dahulu letak PCB ke workspace CNC tersebut.

\section{DAFTAR PUSTAKa}

[1] E. Prianto and H. S. Pramono, "Proses Permesinan Cnc Dalam Pembelajaran Simulasi," J. Edukasi Elektro, vol. 1, no. 1, pp. 62-68, 2017.

[2] D. R. Patel, "Fabrication of Low Cost CNC Engraving Machine," Int. J. Res. Appl. Sci. Eng. Technol., vol. 6, no. 4, pp. 4850-4855, 2018.

[3] A. A. Fuadzi, I. Santosa, and G. R. Wilis, "Instrumen Kendali Mesin Cnc Portable Berbasis Microcontroller Arduino Dan Modul Cnc Shield," $1 s t$ Mech. Eng. Natl. Converence, 2018, pp. 87-96, 2018.

[4] N. K. Mukhofidhoh, "Rancang Bangun Mesin Pengebor PCB Mini Otomatis Berbasis Arduino UNO," J. Tek. Elektro, vol. 7, no. 1, pp. 9-16, 2018.

[5] D. K. Pradana, "Rancang Bangun Cnc Milling Machinehome Made," Teknol. Elektro Vol.10 no.l, vol. 10, no. 1, pp. 35-41, 2011.

[6] A. R. Sonawane, A. B. Rane, and D. S. S. Sudhakar, "Development of a3-Axis Cnc Milling Machine With an Open Source Controller," Int. J. Res. Eng. Technol., vol. 06, no. 08, pp. 9-15, 2017.

[7] P. Gadhe, V. Jangir, and M. Yede, "Design and Implementation of PCB Using CNC," Int. Res. J. Eng. Technol., vol. 4, no. 2, pp. 2-5, 2017.

[8] D. G. Subagio, Teknik Pemrograman Cnc Bubut Dan Freis. Jakarta: Yayasan Obor Indonesia, 2008.

[9] Surwanto, Mahir Permesinan CNC Milling. Yogyakarta, 2018.

[10] M. Amala and S. Widyanto, "Pengembangan Perangkat Lunak Sistem Operasi Mesin Milling Cnc Trainer," J. Tek. Mesin, vol. 2, no. 3, pp. 204-210, 2014.

[11] V. N. Febrianto, "Aplikasi Kontrol PID untuk
Pengaturan Putaran Motor DC pada Alat Pengepres Adonan Roti (Screw Conveyor)," Jur. Tek. Elektro Fak. Tek. Univ. Brawijaya, pp. 1-6, 2014.

[12] A. Restu, J. Wiriawan, and A. Irawan, "Pengaturan Kecepatan Motor DC dengan Kontrol Proporsional Integral Derifatif ( PID ) Berbasis LabView," Telekontran, vol. 4, no. Oktober, pp. 13-24, 2016.

[13] D. Erison, "Perancangan Mesin Bor PCB Menggunakan CNC: Tatap Muka Pergerakan Mesin CNC Secara Otomatis Menggunakan Visual Basic," Institut Teknologi Sepuluh Nopember Surabaya, 2017.

[14] M. Zulfikar, "Apa Itu Fritzing?," 2015. [Online]. Available:

http://zulfikar218.blogspot.com/2015/05/apa-itufritzing.html.

[15] P. Sugiri, "Final Project Design of Computer Based Automatic," UNIVERSITAS SANATA DHARMA YOGYAKARTA, 2015.

[16] I. Widhiada, W. Yuda Ade Putra, and C. Indra Partha, "Auto Tuning PID Controller Untuk Mengendalikan Kecepatan DC Servomotor Robot Gripper 5 Jari," J. Energi Dan Manufaktur, vol. 7, no. 2, pp. 187-192, 2014. 